\title{
A REVISTA AMERICANA COMO UM VEÍCULO DE SONHOS E A ILUSÃO AMERICANA, DE EDUARDO PRADO - REPRESENTAÇÕES DE PAN-AMERICANISMO (1909 - 1919)
}

\author{
The Revista Americana as a vehicle of dreams and illusions - representations of \\ pan-americanism in the Revista Americana and A Ilusão Americana, of Eduardo \\ Prado (1909-1919)
}

La Revista Americana cómo vehículo de sueños y ilusiones - representaciones de pan-americanismo en la Revista y A Ilusão Americana, de Eduardo Prado

(1909-1919)

\author{
Larissa Milanezi Fabriz \\ Doutoranda do PPGHIS/UFES \\ lmfabriz@gmail.com
}

\section{Resumo}

O presente trabalho analisa a Revista Americana (1909-1919), publicação oriunda do Ministério das Relações Exteriores do Brasil, como um espaço de opinião pública e comunidade interpretativa portadora de um conjunto de práticas específicas que autorizavam a publicação de artigos. Analisaremos como a Revista, que fora qualificada por seus editores como um veículo de sonhos, também se tornou portadora de ilusões em virtude das limitações que veiculou a respeito de outros povos e da imigração no continente americano. Para tanto, analisamos artigos publicados na Revista e o livro A Ilusão Americana, do brasileiro Eduardo Prado. Nossas conclusões apontam que as restrições defendidas por esses intelectuais carregavam representações de determinados grupos de imigrantes como aqueles que comprometeriam a paz e o desenvolvimento do continente.

Palavras-chave: Imigração. Paz. Solidariedade Continental.

\begin{abstract}
The paper explores the publication Revista Americana, sponsored by the Ministry of Foreign Affairs, as a space of public opinion and interpretative community carrier of a set of standards which allowed the publication of articles. It released on a non-continuous basis between the years of 1909 and 1919 and became a field to disseminate several aspects of politics, culture and history of Brazil and others south-American republics. It aims understand which were the representations of American continent and peace, and also the restrictions to immigration in the continent, from reading the issues of the corresponding years of the periodic and the book A Ilusão Americana, written by Eduardo Prado. Our conclusions indicate that those intellectuals discussed concerning a peace that they still didn't know in order to avoid war, in the American continent, that also was not their reality.
\end{abstract}

Key Words: Immigration. Peace. Continental solidarity. 


\section{Resumen}

Este artículo analiza la Revista Americana (1909-1919), publicación oriunda del Ministerio de las Relaciones Exteriores de Brasil, como espacio de opinión pública y comunidad interpretativa que carga un conjunto de prácticas específicas que autorizaban la publicación de artículos. Analizaremos cómo la Revista, que fue calificada por sus editores como vehículo de sueños, también se tornó portadora de ilusiones debido a las limitaciones que vehiculó en respeto de otros pueblos y de la inmigración nel continente americano. Para tanto, analizamos artículos publicados en la Revista y el libro "A Ilusão Americana”, del brasileño Eduardo Prado. Nuestras conclusiones apuntan que las restricciones defendidas por estos intelectuales cargaban representaciones de determinados grupos de inmigrantes, como aquellos que comprometerían la paz y desarrollo del continente.

Palabras-claves: Inmigración. Paz. Solidariedad Continental.

\section{INTRODUÇÃO}

A Revista Americana, fonte histórica privilegiada deste artigo, foi um periódico brasileiro, que circulou de forma não contínua entre 1909 e 1919, e portava o projeto de cooperação intelectual internacional, a partir de uma ideia de construção da paz. A revista foi criada e dirigida, inicialmente, pelos intelectuais e diplomatas Arthur Guimarães de Araújo Jorge e Delgado de Carvalho e pelo jornalista pernambucano Joaquim Vianna, e foi patrocinada Ministro das Relações Exteriores do Brasil José da Silva Paranhos, o Barão do Rio Branco. O Barão é lembrado por ter solucionado questões lindeiras do país sem o recurso da guerra. Acreditamos que o periódico fosse percebido como parte da política de aproximação cultural com os vizinhos e que se tornou espaço de circulação de representações de América e Brasil, em um momento em que a diplomacia nacional passava a ganhar novos contornos e objetivos. Dessa forma, pretendemos analisar a revista como um veículo de sonhos, que portava expectativas e projetos de futuro para o continente americano que seria sinônimo de paz, modernidade, solidariedade e civilidade, mas que também portava ilusões e exclusões.

Pensamos que a Revista fosse parte do projeto da política externa do Barão do Rio Branco visto que seus editores estavam ligados à diplomacia. Segundo Barros (2005), Arthur Guimarães de Araújo Jorge, alagoano que iniciou sua atividade diplomática no Rio de Janeiro aos 21 anos, como auxiliar do árbitro brasileiro no Tribunal Arbitral Brasil-Bolívia, Carlos Augusto de Carvalho. Em 1907, tornou-se auxiliar do gabinete do Barão do Rio Branco, de quem foi um dos mais próximos colaboradores. Em 1909, por sugestão e patrocínio do Barão 
do Rio Branco fundou a publicação internacional que é objeto de análise desta pesquisa. Após a morte do Barão, deu continuidade à publicação da Revista e passou a chefiar a legação em Montevidéu e em sequência foi removido para Lisboa, onde ficou até o seu falecimento. Além de ser organizador da Revista Americana, Araújo Jorge também publicou na Revista do IHGB (Instituto Histórico e Geográfico do Brasil).

Segundo Vale (2009), Carlos Delgado de Carvalho foi o primeiro geógrafo brasileiro e apesar de ter vivido a maior parte de sua vida e ter recebido toda a sua formação na Europa, interessou-se pelo Brasil ao escrever sua tese de doutoramento sobre este país. Veio então para o Brasil e trabalhou no Jornal do Commercio, em que escrevia artigos de política internacional utilizando seus contatos europeus e em 1909 começou a dirigir a Revista Americana. Além disso, era professor/autor (GASPARELLO, 2013), visto que além de exercer sua cátedra no Colégio Pedro II, publicou livros didáticos de história e geografia que contribuíram para a configuração desses saberes, e também homem de letras, pois tinha uma formação e atuação diferenciada e associada ao mundo dos livros. Fazia parte do grupo de intelectuais que ocupava cargos na alta administração, na diplomacia ou na administração intelectual.

Joaquim Vianna, por sua vez, além de ser organizador da Revista Americana, era funcionário do Itamaraty e jornalista que publicou no Almanaque Brasileiro Garnier e na Revista Kosmos ${ }^{l}$ suas reflexões a respeito da queda do Império de D. Pedro II e o abolicionismo.

Ou seja, além de diretores do periódico, os intelectuais apresentados acima tinham vínculo estreito com o Itamaraty e com o Barão do Rio Branco. Ademais, ao fazer leitura dos índices das revistas, percebe-se a grande quantidade de intelectuais brasileiros, funcionários do Itamaraty, que publicaram artigos com temáticas ligadas a interesses do ministério das relações exteriores do Brasil.

\section{O CONTEXTO HISTÓRICO DA CRIAÇÃO DA REVISTA AMERICANA}

\footnotetext{
${ }^{1}$ Dantas (2007) analisou a revista Kosmos, literária e cultural, que circulou entre 1904 e 1909 e o Almanaque Brasileiro Garnier que circulou nos anos 1903 e 1904; periódicos em que intelectuais se dedicaram a pensar sobre o Brasil em muitas visões e versões e as estratégias escolhidas para dar corpo à missão de abrir os caminhos da nação, conforme se auto atribuíam. Esses intelectuais julgavam que o povo e a nação estavam por ser feitos.
} 
O contexto histórico brasileiro no início do século XX, período de criação da Revista, foi analisado por muitos autores que destacam a mudança do eixo diplomático brasileiro da Europa na busca de um favorecimento de relações e aproximação com os Estados Unidos e de forma mais lenta com outros países da América Latina. Acreditamos, no entanto, que esse novo direcionamento não significou um descarte das relações com o velho continente, mas sim um redimensionamento das mesmas.

As análises feitas por Feldman (2009, p. 535-592) foram elucidativas, no sentido de esclarecer que o período republicano foi um momento de retomada de tradições imperiais na política externa, visto que tanto nas relações bilaterais (principalmente com os Estados Unidos), bem como em conferências multilaterais (como a III Conferência Internacional Americana em 1906 e II Conferência de Paz em 1907), os representantes brasileiros atuaram pautados nos eixos temáticos civilização/barbárie e soberania/modernidade. Ao que parece, tanto Joaquim Nabuco (diplomata brasileiro escolhido para ocupar a embaixada em Washington entre 1905-1909) quanto Ruy Barbosa (diplomata escolhido para representar o Brasil na Conferência de Paz de Haya de 1905) destacaram em seu discurso a modernização como requisito para a participação nessas conferências.

Da mesma maneira, a categoria civilização parece ter sido utilizada por esses representantes diplomáticos brasileiros com o intuito de distinguir o Brasil, Argentina e Chile dos demais Estados latino-americanos, no sentido de que os três primeiros haviam feito bom uso de sua independência, ou estava no caminho de melhoramentos morais e materiais. Segundo o mesmo autor, os dois diplomatas demonstravam preocupação com o quadro interno do Brasil, ainda mal visto durante a realização da II Conferência de Paz. Daí inferimos que o argumento de Brasil como país civilizado, como herdeiro da cultura europeia, seria fundamental no sentido de adquirir espaços de representatividade internacional. Este teria sido o principal argumento de Ruy Barbosa, enquanto, Joaquim Nabuco falava de um Brasil que prezava pela igualdade de nações, na certa para minimizar os receios dos outros países latinoamericanos em relação à aproximação fomentada cos os Estados Unidos. A própria preocupação de Rio Branco com a escolha de diplomatas qualificados por seus contemporâneos como cosmopolitas e elegantes ${ }^{2}$ para representar o Brasil demonstra uma preocupação de fazer o país agregar uma imagem de credibilidade frente às outras nações.

\footnotetext{
${ }^{2}$ Em estudos anteriores, constatamos que a escolha de Joaquim Nabuco para ocupar a embaixada brasileira em Washington (1905-1909) também esteve relacionada com o seu porte e beleza física, afinal ele seria a representação do Estado brasileiro nos Estados Unidos - a representação em seu sentido mais simples. Percebemos isso ao notar a frequência com que o nome do diplomata aparecia em periódicos da época como o
} 
Ainda que Feldman tenha destacado os aspectos acima como permanências na mudança de regime político monárquico para republicano, é notável um favorecimento de relações internacionais com os norte-americanos e em menor medida com os países latino americanos. Parte desse relacionamento preferencial com os países do próprio continente pode ser explicado a partir da tese de Compagnon (2014), que destaca que nas quatro primeiras décadas do século XX, a intelectualidade latino-americana foi caracterizada por uma crise de identidade e por reflexões a respeito dos destinos da nação. Segundo o autor, esta ponderação aos poucos se emancipou de modelos europeus, que naquele momento passavam a ser considerados obsoletos. Elites políticas e intelectuais se dedicaram a fazer um balanço da história desses países jovens que permaneciam economicamente frágeis e politicamente instáveis. Para além da questão da falência da Europa enquanto modelo de civilização, o momento da criação do periódico foi marcado pela ascensão econômica dos Estados Unidos no cenário Internacional (PEREIRA, 2005, p. 111-128) e conflitos na Europa decorrentes do Imperialismo (CASTRO, 2012) e, por isso, houve uma tentativa por parte do Ministro das relações exteriores de abrir o leque das relações internacionais para os países do mesmo continente.

Bethell (2012, p. 53-78) ainda afirmou que em fins do século XIX, ao mesmo tempo em que os Estados Unidos intervieram na República Dominicana, ocuparam Cuba e Porto Rico e divulgaram o Corolário Roosevelt na Doutrina Monroe, realizaram a Primeira Conferência Pan-Americana em Washington, cujo objetivo era promover não apenas o comércio, como também afirmar a liderança norte-americana no hemisfério ocidental das Américas, como uma unidade separada da Europa. Por parte das nações hispano-americanas, havia suspeita e desconfiança ante este novo interesse norte-americano, mas o Brasil passou a desenvolver relações mais amistosas com os Estados Unidos.

De acordo com a interpretação de Bueno \& Cervo (2008), Rio Branco percebeu o peso dos Estados Unidos na nova distribuição do poder mundial e o fato de que a América Latina estava em sua área de influência. Dessa forma, o Brasil não tinha alternativa ao estreitamento das relações com os norte-americanos, descartando a possibilidade de uma aproximação com uma potência Europeia. A amizade norte-americana não só assumia um caráter defensivopreventivo, como lhe permitia jogar com maior desembaraço com os seus vizinhos. O

The Washington Post e The New York Times, seja sobre banalidades como também eventos formais e de grande importância política internacional. Ver em FABRIZ, L.: Joaquim Nabuco: pan-americanismo, circulação de representações e relações de poder (1905-1910), Orientadora: Juçara Luzia Leite, Dissertação (Mestrado em História), UFES, CCHN, 2014. 
diplomata Joaquim Nabuco, escolhido por Rio Branco para representar o Brasil em Washington, defendia que o Brasil, juntamente com os Estados Unidos lideravam a criação de um continente neutralizado para a paz, livre e inacessível das influências europeias.

Dessa forma, reconhecemos no início do século XX uma americanização da política externa brasileira, no sentido de que os intelectuais começaram a pensar semelhanças como o tamanho continental do Brasil e Estados Unidos, além dos vastos recursos naturais e enorme potencial econômico e de serem democracias estáveis e essencialmente diferentes do restante da América Latina. Pensamos que essa ideia de americanização esteve principalmente associada ao ministério de Rio Branco (1902-1912) e à atuação de Joaquim Nabuco enquanto embaixador em Washington (1905-1909). O diplomata Joaquim Nabuco estava em consonância com o projeto maior da construção da identidade internacional. Dentro desse projeto maior, o Estado brasileiro teve uma função fundamental no processo de aproximação internacional: "o de assegurar e facilitar o fluxo de trocas que os homens espontaneamente estabelecem entre si" (RIBEIRO, 1989, p. 24) e aproveitar dos canais naturais de comunicação para atribuir uma dimensão cultural às relações diplomáticas entre os Estados. ${ }^{3}$

Enquanto a política do "Big Stick” gerava desconfianças entre as Repúblicas hispanoamericanas, Rio Branco tranquilizava os ânimos mais exaltados afirmando que o Brasil não devia temer a política yankee (termo usado frequentemente pelos intelectuais brasileiros do início do século XX em referência aos norte-americanos), uma vez que não apresentávamos um cenário interno instável.

Ao mesmo tempo em que tentou uma aproximação com os norte-americanos, Rio Branco buscou solucionar os conflitos fronteiriços com os países vizinhos sul-americanos, em uma tentativa de aumentar a influência geopolítica do Brasil. Durante sua gestão do Ministério das Relações Exteriores, percebia o Brasil como carente de recursos concretos (poderio militar e economia forte) e de recursos simbólicos (prestígio, política externa confiável). Dessa forma, organizou a sua política viabilizando recursos que nos permitissem compensar tais deficiências. A política territorial passou a obedecer aos tratados coloniais, ao princípio do uti possidetis ${ }^{4}$ e às negociações bilaterais. $\mathrm{O}$ arbitramento era considerado com

\footnotetext{
${ }^{3}$ Podemos perceber que a atuação de Joaquim Nabuco teve esta dimensão, visto que ele falava dos aspectos culturais das nações e participava do cotidiano dos norte-americanos, oferecendo banquetes e se relacionando com figuras locais proeminentes - Nabuco era figura frequente nos periódicos de Washington e de New York.

${ }^{4}$ Segundo Goes Filho (2015), o mesmo fora concebido principalmente pelo brasileiro Alexandre de Gusmão, na época Secretário Particular de D. João V, estruturou-se em torno de dois princípios: o das "fronteiras naturais", como são os cursos dos rios e as cumeadas das montanhas, e o do uti possidetis, que determina que cada parte conserve o que ocupa no terreno. Ganzert (1934) e Tambs (1966) afirmam que o Brasil rejeitou a aplicação do uti
} 
ressalvas por Rio Branco e os limites que foram estabelecidos depois de 1902 (resolução da Guiana Inglesa) restringiram-se a negociações bilaterais, ou seja, o Barão realizou o desenho do contorno do país sem o recurso da guerra e, desta maneira, fundamentou o princípio do pacifismo: o Barão conduziu suas negociações pela celebração de tratados e sem derramamento de sangue.

Ao que parece, o Barão via o Brasil em uma situação diferenciada dentro do continente que se justificava por uma visão de Brasil como portador de características que lhe eram únicas e o destacavam em relação aos outros países, quais sejam de país moderno, pacífico $^{5}$, civilizado e cordial, que se aglutinavam na representação de pan-americanismo.

Na Revista Americana é possível perceber um reflexo dessas propostas da política internacional que valorizavam o papel da América como continente da paz e da diplomacia. Acreditamos que se tratava de um projeto de posicionamento a favor da aproximação entre o Brasil e os países vizinhos e que caberia ao Itamaraty o papel de protagonista dessa nova ordem da diplomacia no continente americano.

Tais conclusões corroboram com o nosso entendimento da Revista como espaço em que circularam representações de paz não apenas de diplomatas brasileiros, mas também daqueles oriundos de outros países. Sabemos que nesse periódico a ideia de paz que se pretendeu fazer circular estava atrelada a uma diferenciação do continente americano em relação ao Europeu pautados na violência ou possibilidade de guerra, pois encontramos entre os artigos a preocupação de pensar como a diplomacia poderia assegurar a continuidade de continente americano como sinônimo de paz, no sentido de cordialidade. Sabemos também que a Revista era parte de uma estratégia para garantir prestígio para o Brasil, cooptando recursos simbólicos por meio desta "amizade": a materialidade de uma aproximação com os

possidetis de jure em favor do uti possidetis de facto, uma doutrina alternativa que determinava o domínio de um território com base na ocupação física e não da possessão colonial. Ainda segundo os mesmos autores, Brasil usou esta doutrina alternativa para argumentar a favor da expansão de seu território através dos anos 1810 e das fronteiras das colônias espanholas como Bolívia e Peru.

${ }^{5}$ Não pensamos nesta pesquisa o conceito de pacifismo conforme defendido por Magri, como um movimento de iniciativa unilateral para romper a uma espiral que produz a guerra; no sentido de sustentar que a Europa Ocidental deveria dar o exemplo durante a Guerra Fria e reduzir seu arsenal militar como única forma de impor negociações autênticas entre as grandes potências por um ato político com alguma esperança de efeito. Tal conceito estaria atrelado a um contexto em que o equilíbrio militar correspondia a mais do que um simples armazenamento de armas, mas também era reflexo de um interior econômico e tecnológico que cada campo poderia mobilizar rapidamente para um esforço de guerra. Em outras palavras, tratava-se de uma ideia de um equilíbrio do terror que se não era suficiente para assegurar a paz efetiva, pelo menos garantia contra uma nova guerra. Na Revista, pensamos em pacifismo enquanto sinônimo de cordialidade; de relacionamento cordial com os vizinhos de quem se conhece a partir dos exemplos e fatos históricos. MAGRI, L.: "O movimento pacifista e a Europa”, em Edward Palmer THOMPSON (Org.): Determinismo e Guerra Fria, São Paulo, Brasiliense, 1985. 
Estados Unidos aumentaria a capacidade de manobra do Brasil no jogo diplomático sulamericano. Com esta estratégia, o Itamaraty procurou dotar o Brasil da capacidade de defender apropriadamente os seus interesses, atuar autonomamente no meio internacional e negociar a paz.

\section{A REVISTA AMERICANA}

Foi nesse contexto que foi criada A Revista Americana; um periódico mensal, impresso pela Imprensa Nacional onde foi possível encontrar representações de América e de pan-americanismo ${ }^{6}$. Pensamos que o Brasil, a partir da política externa adotada por Rio Branco, colocava-se de maneira positiva ante ao pan-americanismo norte-americano, apoiando e promovendo iniciativas nesse sentido.

O título cosmopolita e abrangente (Revista Americana: Sciencias - Artes - Letras Política - Philosophia - História - Religiões) é capaz de representar a diversidade de assuntos que foram contemplados nas discussões: em todos os volumes analisados foi possível encontrar poesias, narrações de mitos e lendas típicos da América Latina, análises econômicas, história da literatura detalhada dos países de origem dos intelectuais que escreviam no território, romances, contos, defesa de questões lindeiras e defesa de alianças continentais. Encontramos nesses mais variados tipos textuais o significado de união panamericana em suas múltiplas perspectivas (incluindo os Estados Unidos ou não; englobando todos os países desse continente ou apenas alguns da América do Sul) e as representações que se esperava atrelar ao país Brasil e ao continente americano. No sumário foi possível saber o nome dos autores e títulos dos respectivos artigos e perceber que os intelectuais brasileiros e diplomatas são recorrentes entre as listas de autores.

Dessa forma, pudemos considerar que este periódico era um espaço de circulação de representações (CHARTIER, 1990), na qual intelectuais latino-americanos divulgavam suas

\footnotetext{
${ }^{6}$ Existiam diferenças entre pan-americanismo, bolivarianismo e monroísmo pan-americano. Em linhas gerais, Bethell afirmou que o pan-americanismo bolivariano, anterior ao norte-americano, tinha como objetivos a implantação de soberanias temperadas por interesses comuns supranacionais, a regulamentação de acordos de comércio, a busca por medidas para evitar a guerra, superar os conflitos de fronteira, uniformizar o direito público, conciliar os litígios por arbitramentos obrigatórios, a criação de um direito internacional latinoamericano visando compensar o esfacelamento político regional resultante das independências políticas. Magnoli explica que o monroísmo pan-americano retomava a ideia de união americana a partir do estímulo das relações comerciais com os países do continente. Bueno \& Cervo asseveram que houve uma tentativa de converter o panamericanismo latino (bolivariano) em instrumento que viabilizasse o programa de dominação capitalista sobre o continente. Nessa vertente, as intenções do governo norte-americano visavam a estabelecer, pela via do panamericanismo, uma reserva de domínio continental e com isso poderiam manter o protecionismo diante das outras potencias capitalistas e o liberalismo regional.
} 
perspectivas e também se apropriavam das mesmas com o intuito de se fazer conhecer o continente americano, narrar aspectos culturais e fatos históricos, além de se elaborar prognósticos para o futuro (KOSELLECK, 2006). Afirmamos isso, pois, claramente, foi por meio desse espaço, que esses representantes proeminentes da intelectualidade do continente, fizeram circular suas perspectivas para o projeto de pan-americanismo. Além disso, os artigos nos demonstraram que é possível atrelar a ideia de pacifismo, modernidade e civilização como representações de pan-americanismo, e que os textos escritos pelos diplomatas e intelectuais também tinham o objetivo de diluir aspectos conflituosos que poderiam existir entre as nações.

Pensando nessa ideia de pan-americanismo ligado a cordialidade, foi possível encontrar, entre os artigos da Revista, um escrito pelo intelectual argentino Francisco Felix Bayon que defendia a necessidade de se criar "asociaciones internacionales que hicieron la vida más barata” (REVISTA AMERICANA, Volume III, Dezembro, 1909, p. 349) e "las visitas que podrían realizarse entre los intelectuales hispano-americanos, anualmente ó cada tempo, á fin de mantener él recuerdo y recoger impressiones.” (Idem.) Segundo o autor, essas visitas seriam responsáveis por aguçar as inteligências que buscam algo novo. Além disso, segundo o autor, "estas variantes de clima sirven también para impedir las asombrosas exclamaciones de los que piensan que sólo en America se cuecen habas y que en ella la justicia es un mito."(Idem). Ou seja, o estímulo de trocas culturais permitiria a quebra de paradigmas negativos que estivessem ligados ao continente, resultando em cordialidade e paz.

Demarchi (1997) qualificou a Revista como uma megalomania do Barão do Rio Branco na apropriação do discurso americanista em prol da hegemonia do Brasil na América do Sul e também para impor a versão brasileira sobre a Guerra do Paraguai em um momento em que a demarcação de fronteiras era um dos pilares do discurso americanista. Além disso, o autor pensou no contexto como um período de transição pela liquidação da influência europeia, "rumo a cultura e economia norte-americanas como referenciais para o país". Concordamos com o autor em relação à tentativa de acomodar-se à supremacia norteamericana para beneficiar-se dela e viabilizar a hegemonia na região sul do continente.

Além disso, o mesmo defendeu que no Brasil, o americanismo se resumiu a um discurso a favor da integração nunca efetivada do que uma indagação do que seria a América; e o Estado teria investido, no início do século XX, na criação de periódicos ambiciosos que foram responsáveis por transformar o discurso americanista de utopia a falácia, dentre eles, a Revista Americana. Aqui, diferente do autor, defendemos que os artigos que foram postos a 
circular eram mais sonhos ou projetos que se esperava concretizar do que um simples falatório que desfez a utopia. Pensamos assim, pois além da questão de tornar conhecidos aspectos naturais e históricos dos países que compõem o continente americano, por meio de uma leitura atenta do artigo que abre o primeiro número da Revista, é possível perceber uma preocupação em se conhecer o aspecto intelectual da América (o continente). Esse movimento, além de permitir o conhecimento da história de cada país, tornaria possível a criação do "amor em relação às tradições” desse lugar.

Dessa forma, a representação de paz pode ser entendida como resultado de um congraçamento moral, daquilo que se admira porque se conhece, fosse um dos objetivos da criação do periódico. Até aquele momento, segundo os autores, esses aspectos estavam sendo ignorados em virtude das grandes distâncias e da pobreza dos meios de comunicação e também da convicção "radicada em todos nós de que as idéas, para ser aceitáveis, necessitam trazer a marca européa e transpor os mares nos bojos dos transatlanticos" ((REVISTA AMERICANA, Volume I, Outubro, 1909, p. 5)

Tais questões formariam o quadro que mostra as causas "por que as gentes americanas se desconhecem voluntariamente" (Idem, p. 5). Essa passagem nos remeteu à ideia de História como Magistra Vitae explicada por Koselleck, da História como mestra da vida, "um cadinho contendo múltiplas experiências alheias, das quais nos apropriamos com um objetivo pedagógico; ou, nas palavras de um dos antigos, a história deixa-nos livres para repetir sucessos do passado, em vez de incorrer, no presente, nos erros antigos", (KOSELLECK, 2006, p. 42), que também carrega a ideia de que a História pode conduzir ao "relativo aperfeiçoamento moral ou intelectual de seus contemporâneos [...] a estrutura temporal da História passada delimitava um espaço contínuo no qual acontecia toda a experimentação possível. ”(Idem, p. 43). Pensamos dessa maneira, pois os artigos publicados na Revista Americana carregam a missão de relatar fatos históricos com o objetivo de instruir e de se fazer conhecer. Portanto, o periódico se trata de um espaço em que se deixariam marcas para as gerações futuras de sonhos e projetos que estavam relacionados com uma dada representação de continente americano pacífico decorrente da cordialidade entre os povos. $\mathrm{Ou}$ seja, um dos objetivos da Revista foi criar um espaço através do qual seria possível conhecer voluntariamente o continente através daquilo que é chamado de "manifestações espirituaes da America [...] a partir da união entre as figuras representativas da intellectualidade desta parte do mundo" (REVISTA AMERICANA, volume I, fascículo I, outubro de 1909, Biblioteca Nacional do Rio de Janeiro, Periódicos - Microfilme: PR-SOR 06249, pp. 5). 
Também o objetivo da Revista, segundo seus editores, era servir como fonte de consulta para futuros estudos. Além disso, percebemos que os intelectuais atribuíram um papel importante para a América no mundo, que estava apta para opinar a respeito de eventos internacionais ou de reforçar o quanto que o restante do mundo estava envolto em uma atmosfera de guerra enquanto o Brasil se dedicava a esta missão de aproximar os países americanos em um sentimento de congraçamento e diluição de conflitos, o que pode ser compreendido como sinônimo de Brasil como aquele que lidera o caminho para o continente da paz.

Dessa forma, acreditamos que a Revista Americana constituiu uma comunidade interpretativa, conceito oriundo dos estudos literários de Fish (1980) que diz respeito a um sistema ou contexto capaz de produzir um consenso em torno da escolha da interpretação a ser atribuída a um enunciado ou conjunto de enunciados. Tal consenso se produz em virtude da existência de uma estabilidade de significados inerente à textualidade, a partir do momento em que indivíduos que se agrupam em torno de um espaço (no caso a Revista Americana), compartilham regras e estratégias de leitura que permitem a coincidência de interpretações. Em outras palavras, as representações de continente americano e pan-americanismo atreladas às de paz, modernidade e congraçamento moral foram postas a circular com um dado significado que era partilhado pelos escritores que ali publicavam.

Aqueles intelectuais que intendiam questionar as representações, não tinham seus artigos publicados. Para além dessa perspectiva, pensamos que a ideia principalmente posta a circular é a de que o continente americano era um conjunto de promessas e potenciais que conferiam a esse lugar um papel decisivo em relação à diplomacia; pois a vocação da América seria para a paz e nota-se um anseio por uma maior participação dos intelectuais no destino deste continente. Essa defesa está relacionada à retórica pan-americanista que portava a associação entre moral americana como um sinônimo de controle das paixões e alucinações, civilização latino-americana como aquela que é a própria liberdade e modernidade no sentido de investimento em meios de transporte e comunicação cada vez mais eficientes. Tal análise nos conduziu a pensar que essa é a justificativa para a ausência de discursos panfletários, como é o caso de Eduardo Prado, na Revista Americana.

Pensando sob ótica da Revista como uma comunidade interpretativa, a apresentação nos deu pistas de quais tipos de textos e que ideias se inscreveriam naquele suporte e seriam postas a circular e demonstrar quais vínculos específicos se pretendia entre os artigos e, também, as representações que seriam aceitáveis. Ainda no texto da apresentação do primeiro 
número, os autores que compunham a Redação, a saber, A. G. de Araújo Jorge, Joaquim Viana e Delgado de Carvalho, destacam que essa aproximação teria como resultado imediato " $o$ congraçamento moral [que] constitue o primeito passo para uma aproximação política cordial e inteligente" e prosseguiu afirmando:

Quando os povos americanos tiverem uma noção exacta do valor das suas fortes qualidades originárias e nativas, ainda não de todo esmaecidas ao inflixo das culturas exoticas; quando reconhecerem que o nosso Continente, tão mal conhecido e ultrajado, constitue, por si só, uma matriz perene de estudos, exames, indagações, um campo vastíssimo referto de problemas interessantes e sugestivos, uma genetriz fecunda de emoções para a imaginativa do poeta, de pontos de vista curiosos para o espirito dos philosophos, para as locubrações dos sábios, então se reconhecerá o tempo inutilmente consumido em questiunculas desinteressantes e obscuras, os annos transcorridos sem a acquisição de um principio sólido para o progresso da America, de uma conquista preciosa para o desenvolvimento de sua vida, politica, econômica, intellectual, de uma contribuição útil para o vasto patrimônio commum da humanidade. (Idem, p. 6)

Pensamos que "congraçamento moral" é paz, ou o que estão dando a ler na Revista é que a paz seria possível no continente a partir desse congraçamento. Sob essa lógica, a América é pensada como parte integrante da comunidade internacional, pois ocupava um novo espaço nas Relações internacionais e uma das missões da Revista seria a de legitimar as revelações que foram feitas "por uma voz autorizada na última conferência da Paz, na Haya."(Ibid. p. 8) ${ }^{7}$.

Os redatores mencionaram que para que essa missão de aproximação política fosse efetivada, seria necessária uma "forte arregimentação de energias [...] dispersas”, uma circulação ativa de ideias e sentimentos entre as pessoas que habitam a América, a penetração das "consquistas espirituaes".

E ao destacar que nas páginas dessa Revista seriam debatidos todos os problemas que se relacionam ao destino das nações americanas, os autores da redação destacam que " $a$ Revista Americana faria o esforço para transmutar o sonho em realidade calorosa e fecunda"

\footnotetext{
${ }^{7}$ Nessa conferência de Paz de Haya, segundo Cardim (2014), o Brasil foi representado por Ruy Barbosa, que se destacou por defender o princípio de igualdade entre as nações. O debate girou em torno da proposta dos EUA, que com apoio da Alemanha e do Reino Unido, pretendiam criar uma Corte Internacional de Justiça composta por juízes permanentes (EUA e dois outros representantes países europeus) e o restante dos juízes teria caráter rotativo. Nessa ocasião, Ruy Barbosa propôs que se decidisse sobre a questão da arbitragem levando em conta que cada signatário tivesse o direito de designar um juiz para o tribunal proposto que em todo litígio cada parte mantivesse o direito de escolher seus juízes nesse tribunal. De acordo com esse princípio, segundo Zimmermann ${ }^{7}$, tendo por base a igualdade, Ruy Barbosa defendeu que todas as nações deveriam possuir igual assento na corte de arbitragem, ficando a critério das partes litigantes a escolha de juízes. Dessa forma, cada Estado poderia indicar quatro nomes para a Corte de Justiça Arbitral.
} 
(Ibid. p. 6) a partir da "aproximação política", do "congraçamento intelectual" e do "engrandecimento moral” das nações americanas.

Lucilo Bueno, colaborador do jornal O Seculo, por sua vez, mencionou o paradoxo de termos tanta semelhança entre os idiomas e, no entanto, permanecermos estranhos:

Quem, na America do Sul, suspeitará de que na nossa literatura há o patrimonio riquíssimo de um Alencar, de um Macedo, de um Gonçalves Dias, de um Machado de Assis? [...] Com a grande facilidade de compreensão de nosso idioma e nós do delles, vivemos apartados, ideando vagamente uma civilização, sem cuidarmos que preciso é conhecer as manifestações de um povo para então amal-o e admiral-o. [...] Os homens de responsabilidade do continente nunca trataram da aproximação fraternal lda intelligencia e só quando algum congresso se reúne em qualquer das capitaes latino-americanas, é que vemos, embevecidos, a revelação de talentos, até então completamente ignorados. (Ibíd. P. 426)

Visto que os objetivos eram muitos e que os intelectuais que publicavam nessa Revista eram portadores de projetos de uma América para um futuro próximo, fica fácil compreender porque a Revista é caracterizada pelos membros da Redação como um veículo de sonhos: ela portaria as representações de América e Pan-americanismo que um dado grupo de intelectuais considerava adequada para aquele momento tendo em vista o campo de experiências e horizonte de expectativas.

Koselleck (2006) defende que não se pode ter expectativa sem experiência e viceversa, e que "todas as histórias foram constituídas pelas experiências vividas e pelas expectativas das pessoas que atuam ou que sofrem." (KOSELLECK, 2006, p. 306). Ou seja, o que queremos afirmar é que a partir do uso da história como conhecimento de experiências alheias, esses intelectuais tentavam projetar nessa Revista, por meio das representações que eram postas a circular, suas expectativas em relação ao que esperavam ser o continente americano, por isso a sentença feliz para designar o periódico como um veículo de sonhos, um portador de horizontes de expectativas que entrelaçavam presente (deles) e futuro (deles).

\section{REVISTA AMERICANA QUE TAMBÉM É VEÍCULO DE ILUSÕES}

Apesar de defendermos que a Revista Americana foi um veículo de sonhos e projetos de intelectuais latino-americanos, os artigos evidenciam recorrentemente que a condição de continente pacífico e moderno fora conquistada em virtude de fatores específicos, cuja continuidade apenas seria possível com algumas medidas. Uma delas seria o controle da imigração, que se não fosse feito, faria com que o elemento estrangeiro significasse uma 
perturbação da paz.

Dentre as questões discutidas no periódico, a fundação de escolas públicas com um programa americano, diferente do europeu e a seleção da imigração seriam as mais fundamentais e, de acordo com o intelectual Francisco Felix Bayon, a Argentina possuía vasta experiência no assunto. Sobre a imigração ele defendeu que

la población, no debe ser libre, sino selecionada, á fin de que venga la mejor, desde que hay que convenir que los que emigran no son los mejores ni los más sábios. Y como la gente de los bajos fondos tienen la rutina por norma, se explica que hayan tres y cuatro generaciones de iguales cualidades, como sucede con los arabes, rusos e italianos, que son tradicionalistas vulgares y torpes. (REVISTA AMERICANA, volume I, fascículo III, dezembro de 1909, Biblioteca Nacional do Rio de Janeiro, Periódicos - Microfilme: PRSOR 06249, pp. P. 348).

Juntamente a essa ideia de criar escolas com um programa propriamente americano, o mesmo autor também sugeriu que as leis não se limitassem a copiar os modelos europeus, "puesto que si proceden en esta forma, nunca se podrán introducir las verdaderas mejoras racionales" e "ante todo debemos ser americanos, y no conviene que apliquemos el método de analogia que cuesta caro y que impide pensar, desarollar la voluntad." (REVISTA AMERICANA, volume I, fascículo III, dezembro de 1909, Biblioteca Nacional do Rio de Janeiro, Periódicos - Microfilme: PR-SOR 06249, pp. P. 351)

As escolas, dessa forma, seriam fundamentais para educar a população para se despertassem neles "sus sentimientos de moral altruista" e também o amor ao Belo e à Arte, visto que "los grandes pueblos como los grandes ciuadanos son los que aman el arte y lo bello porque en ellos está la ciencia universal" (Ibid., p. 350). Nesse trecho, fica evidente que o objetivo de montar um programa escolar era o de contribuir para um congraçamento moral baseado nas boas maneiras e moral americana e também de moldar o comportamento do estrangeiro que já havia entrado no continente.

Além disso, o autor destacou o quanto seria importante controlar o fluxo migratório para que a América não se convertesse em refúgio de "hombres resacas ni declarados fuera de la ley que sólo sirven para alterar el orden público.”(Ibid. p. 350). Segundo Francisco Bayon, era de fundamental importância que fosse realizado um controle da imigração, pois junto com algumas nacionalidades vinham ideias que poderiam atrapalhar o desenvolvimento do conhecimento e da solidariedade em território americano.

Para nuestros pueblos son peligrosas estas ideas de antipatriotismo [...]. hay que ser ciudadano y soldado; patriota y humanista. Illustrase es vivir feliz; atacar la patria es demonstrar poco juicio y mucha torpeza. La libertad está 
con las nacionalidads; la esclavitud con el socialismo. Elijamos cual es lo mejor camino para nuestra America. (Ibid. p. 351).

Norberto Piñero, outro argentino, foi defensor da imigração como condição para o desenvolvimento social da Argentina, mas conforme nossas análises, havia uma série de propostas de exclusões e entraves para a entrada de imigrantes em território Argentino. $\mathrm{O}$ autor se refere à raça como uma questão de eugenia. Propôs a restrição das correntes migratórias da Ásia e da África para impedir a entrada na nação de “delincuentes, prófugos, processados por delitos comunes, inválidos, vagos, mendigos, imbecíles, locos, enfermos contagiosos o repugnantes [...]” (Ibid. p. 326) e não excluir a imigração europeia. Foi veemente na questão da necessidade de proibir a imigração síria a qualquer custo, que, nas palavras do autor

"lejos de ser benéfica, es nociva a la salud nacional. Sus membros, excepción hecha a una minoria muy exígua, no vienen a labrar la tierra, mejorar las industrias ni enseñar las ciencias y las artes. Vienen a ejercer un trafico mezquino que confina con la vagância, y viven aislados, en barrios separados o andan errantes por todo el país, a través del cual pasean sus baratijas y el ejemplo de su vida inferior." (Ibid. p. 326)

Ou seja, o controle da entrada de imigrantes parece ser um ponto comum entre os intelectuais da Revista Americana, no sentido de que propunham entraves a determinados povos. Nos perguntamos se esses entraves estariam relacionados com questões de cunho religioso, visto que predominava nesse contexto e entre as representações estudadas a ideia de moral cristã. Se pensamos assim, podemos afirmar que a Revista Americana também era portadora de ilusões e de preconceitos compartilhados naquele período.

\section{A ILUSÃO AMERICANA, DE EDUARDO PRADO}

A partir da análise dos artigos que foram veiculados na Revista Americana, foi possível perceber quais representações de continente americano que os intelectuais desse espaço intentaram fazer circular no início do século XX. Esse periódico portava um presentepassado que faz menção um futuro, visto que são intelectuais contemporâneos entre si, que, ao discutir questões que são próprias ao seu presente usam como ferramenta análises históricas (apreendida pelos mesmos como mestra da vida), com o objetivo maior de elaborar prognósticos considerados favoráveis para o continente.

Já vimos que se tratava de uma representação de pan-americanismo que aglutinava as 
categorias de paz, modernidade, solidariedade, civilidade e imigração. Tais categorias surgem nos artigos que foram publicados na Revista sugerindo dois eixos de discussão: a aproximação entre Brasil e Estados Unidos e a aproximação entre Brasil e os demais países que compunham o continente latino-americano. Em ambos eixos, o Brasil, ao menos na opinião de intelectuais brasileiros, que contavam maior quantidade no periódico, é ressaltado como o país que poderia protagonizar a liderança no continente.

Retomamos aqui que compreendemos a Revista como um espaço de sociabilidade e de circulação de representações que são originadas e originam práticas culturais que seriam os banquetes como os promovidos por Joaquim Nabuco em Washington e o próprio ato de escrever na Revista. Em que pese esse periódico não ser homogêneo e nem consensual, visto que é fácil perceber os embates de representações, nos perguntamos quais discursos eram aceitos como legítimos nessa revista; em outras palavras, nos questionamos quais eram os mecanismos que permitiram a esses homens de outros tempos se inscreverem como um intelectual da Revista.

Nos chamou atenção que o intelectual brasileiro Eduardo Prado que não publicou no periódico durante o período analisado, foi criticado por alguns dos interlocutores da Revista, como por exemplo Araripe Junior. Prado escreveu o livro A Ilusão Americana, que tivera sua primeira edição proibida no Brasil, conforme podemos verificar na introdução à segunda edição escrita por Ruy Barbosa:

\begin{abstract}
As nossas contas com os negociantes de fraternidade norte-americana são ainda mais sérias. Entretanto, há entre nós, nativistas, que protejam estátuas a Monroe, julgam praticar ato de republicanos, suscitando para amparo do Brasil o protetorado dos Estados Unidos. Se esses entusiastas quisessem refletir, eu lhes recomendaria o folheto precioso com que o Sr. Eduardo Prado acaba de enriquecer a literatura brasileira: A Illusão Americana ( $2^{\mathrm{a}}$ edição). Este livro teve singular destino: no Brasil foi proibido uma hora depois de posto à venda, isto é, proibido antes de lido [...] A sua publicação em São Paulo comprometia as boas relações entre o Marechal Peixoto e o presidente Clevelend.[...] esse opúsculo, absolutamente novo no assunto, em que, como repositório de verdades ignoradas, é o mais oportuno serviço ao Brasil. (PRADO, 2003, p. 8).
\end{abstract}

A primeira edição do livro fora publicada em 04 de dezembro de 1893, nas livrarias de São Paulo e "vendidos todos os exemplares prontos nesse dia, foi à livraria o chefe de polícia e proibiu a venda." (Ibídem, Apêndice).

O livro tem como objetivo a crítica incisiva à tentativa de aproximação entre Brasil e Estados Unidos que se pretendia naquele momento, pois na opinião dele se tratava de uma "insanidade da absoluta confraternização que se pretende impor entre Brasil e a grande 
república anglo-saxônia, de que nos achamos separados não só pela grande distância, como pela raça, pela religião, pela índole, pela língua, pela história e pelas tradições do nosso povo." (Ibíd. p. 9).

Para ele, a tentativa de aproximação entre os dois países não deveria ter adquirido tamanha importância, visto que deveria ser considerada um despropósito em face da atuação interesseira dos norte-americanos entre os países latino-americanos. Ele criticou argumentos chave do Barão do Rio Branco e Joaquim Nabuco no sentido de promover essa aproximação, mas para além de fazer uma crítica contundente aos Estados Unidos, ao longo dessa obra, o autor rebate justamente as categorias que a Revista Americana intendeu fazer circular quando, repetidamente, destacou que a "fraternidade americana é uma mentira", pois

Tomemos as ações ibéricas na América. Há mais ódios, mais inimizades entre elas do que entre as nações da Europa. O México deprime, oprime e tem, por vezes, invadido a Guatemala, que em sangrentíssimas guerras com a República de El Salvador, inimiga rancorosa da Nicarágua, feroz adversária de Honduras, que não morre de amores pela República da Costa Rica. A embrulhada e horrível história de todas estas nações é um rio de sangue, é um contínuo morticínio. E onde fica a solidariedade americana, onde fica a confraternização das repúblicas? (Ibid. p. 12)

Concluímos que o autor não publicou na Revista Americana não apenas por ser contra uma aproximação entre Brasil e Estados Unidos, mas principalmente porque criticava a ideia de união pan-americana e reforçava o quanto essa atitude era um paradoxo frente aos inúmeros conflitos que existiam entre os países do continente. Dessa forma, enquanto os intelectuais da Revista Americana insistiam sistematicamente na ideia de continente americano como sinônimo de paz, Prado escrevia que era necessário desvincular a ideia da independência dos países latino americanos da solidariedade dos Estados Unidos. Seria mais lógico que esse movimento fosse vinculado à Inglaterra, pois haveria sido neste país que se iniciou uma atividade de panfletagem a favor dos movimentos de independência. Mesmo a proclamação da Doutrina de Monroe havia sido feita tardiamente, apenas 15 meses depois a ocorrência da Santa Aliança.

Até então, a atitude dos Estados Unidos tinha sido toda de reserva, de abstração, e, para uma nação que se quer apresentar como a protetora dos latino-americanos, é forçoso confessar que essa política não era de fraternidade, mas sim de egoísmo. Ainda em 1819 o governo americano recusara receber os cônsules nomeados por Venezuela e pelo governo de Buenos Aires, alegando vários pretextos, e só a 9 de março de 1823 é que reconheceu a independência das repúblicas espanholas. Fortalecido e animado pela iniciativa da Inglaterra, em 2 de dezembro de 1823, o presidente Monroe disse na sua mensagem [...]. a nunca assaz ludibriada e escarnecida ingenuidade sul-americana viu nesta declaração um 
compromisso formal, solene e definitivo de aliança com os Estados Unidos, aliança tão sensata aliás como a do pote ferro como a do pote de barro. [...] há 71 anos que, por palavras, atos e omissões, o governo de Washington praticamente demonstra a significação restrita, e, por assim dizer, platônica das palavras de Monroe, e, ainda hoje, há quem tenha a superstição de tomar aquilo ao pé da letra. (Ibid. p. 17)

Nessa linha de raciocínio, Prado prosseguiu com o resgate de fatos históricos com o intuito de reforçar a ideia de que os Estados Unidos "não estavam por forma alguma dispostos a fazer suas as brigas da América Latina com as potências europeias." Fez isso com a intenção de reforçar a incoerência da Doutrina Monroe visto que os Estados Unidos em momentos significativos da história da América Latina não haviam se posicionado de forma solidária ao continente.

Eduardo Prado pensava a Doutrina Monroe como sinônimo de incoerência, omissão, ameaça, atormentação e beligerância em virtude dos exemplos do Panamá, Nicarágua e México, que citou em sua obra. Com toda a sua argumentação, procurou reforçar o quanto norte-americanos não estavam empenhados com a causa do continente, mas sim utilizavam sua expressividade para reclamar indenizações ou quando estavam estimulados por causas econômicas, como fora o caso do Panamá, após a construção de um caminho de ferro no istmo deste país.

E seguiu fazendo denúncias de financiamento norte-americano de mão de obra escrava proveniente da China que era usada para trabalhar no Peru. Ao mesmo tempo, procurou agregar o valor de nação detentora de espírito cristão à Inglaterra, quando atribuiu a este governo o resgate de polinésios que haviam sido escravizados por peruanos quando estes invadiram a Ilha de Páscoa, no Chile:

Recolhidos a bordo de um navio de guerra inglês, os desgraçados que tinham escapado à ferocidade americana foram restituídos às suas ilhas, devendo sua salvação ao espírito cristão da Inglaterra, às sociedades humanitárias compostas de burgueses, de mulheres religiosas e de curas de aldeia, que naquele país, que é o mais poderoso e livre do mundo, têm bastante influência para mover a imprensa, a opinião e o governo em favor de uns míseros selvagens, perseguidos a milhares de léguas de distância. (Ibid. p. 52)

Ainda para reforçar a ideia de Estados Unidos enquanto país violento no trato com seres humanos, além do caso supracitado dos polinésios, Eduardo Prado destacou o preconceito e desrespeito com o qual foram tratados chineses e índios em seu território durante o período da guerra da China (1859) quando afirmou que 
Os pobres chins são linchados nos Estados Unidos sem nenhuma forma de processo, sendo até as vezes queimados vivos. Os Estados Unidos obtiveram da China um tratado de amizade, comércio e navegação, em virtude do qual era livre a entrada e saída dos chins e dos americanos, reciprocamente, nos dois países. Pois, não obstante a solenidade desse compromisso nacional, o Congresso americano votou uma lei proibindo a entrada dos chins nos Estados Unidos. [...] A política norte-americana, em relação aos índios que ela ainda não acabou de exterminar, é uma política de ferocidade inacreditável neste final de século XIX. [...] O governo falta com cinismo à fé dos tratados, mata os índios à fome e à tiro, rouba-lhes a fé onde os instala. (Ibid.p. 74)

Esta relação interesseira e de extorsão que partia dos norte-americanos também se estendia ao Brasil, que, segundo Eduardo Prado, teria sido alvo de uma trama a partir da qual Nova Iorque pretendia uma expedição pelo Pará e o Amazonas (1853). Ao que parece, tratava-se de uma expedição que seria comandada pelo oficial da Marinha americana e funcionário público Maury, que juntamente com outros americanos falavam muito da possibilidade de enriquecimento na região amazônica. Prado destacou que

Estas pretensões americanas sobre o Amazonas tornaram-se então ameaçadoras. Em seguida à exploração feita no grande rio pelo tenente Herndon, da marinha americana (que aconselhara aos brasileiros o uso da força para os índios, em vez de catequese), começou a agitação americana a propósito do Amazonas. Foram despachados agentes diplomáticos para o Peru e para a Bolívia, com o fim de levantarem os governos daqueles países contra o Brasil e de os aconselharem a pedir o auxílio dos Estados Unidos. (Ibid., p. 68).

Fez isso com a intenção de associar o comportamento do governo norte-americano como momentos anteriores, especialmente os relativos ao México (região do Texas) e à América Central. Em outras palavras, o que se percebe no discurso de Eduardo Prado é a constante associação da política internacional dos Estados Unidos como "egoística, arrogante às vezes, outras vezes submissa, segundo os interesses da ocasião. E, em todo o caso, ela nunca se deixa guiar por sentimentalismos de forma de governo." (Ibid., p. 70)

Prado também abordou o interesse comercial deste país quando ressaltou que

Tratados de comércio! Eis aí a grande ambição norte-americana, ambição que não é propriamente do povo, mas sim da classe plutocrática, do mundo dos monopolizadores que, não contentes com o mercado interno de que eles têm o monopólio contra o estrangeiro, em virtudo das tarifas proibitivas nas alfândegas, em detrimento do pobre que sevê privado de grande benefício que a concorrência universal the traria com o forçado abaixamento dos preços. (Ibid., p. 76). 
Teria sido com o intuito de dar saída a seus produtos e de criar-lhes vantagens especiais nos mercados estrangeiros, que os Estados Unidos tentaram impor tratados de reciprocidade comercial a todos os países da América enquanto Blaine ocupou o cargo de Secretário de Estado.

No texto também podemos entender Estados Unidos como nação individualista e que esteve sujeita aos desmandos de Blaine, pois ao descrever a Primeira Conferência panamericana no ano de 1889 expressou o programa desta conferência, que consistiu na adoção do arbitramento obrigatório para a solução de conflitos internacionais; na celebração de tratados com o governo de Washington estabelecendo uma parcial ou total e recíproca isenção de direitos de importação entre o país contratante e os Estados Unidos; e um estudo para, que ele qualificou como para encher tempo, sobre um caminho de ferro dos Estados Unidos à Patagônia, ligando entre si as repúblicas americanas. Sobre a questão dos arbitramentos, Eduardo Prado julgou-o da seguinte maneira, falando ironicamente a respeito da fraternidade e lealdade latino-americana:

A questão do arbitramento não ofereceu grandes dificuldades. Em matéria de promessas, de tratados e de compromissos internacionais, as repúblicas da América não são difíceis. O Corpus Diplomaticum sul-americano, isto é, a coleção dos seus tratados, dos seus acordos e das suas convenções, é enorme. Fazem-se, desfazem-se, esquecem-se e violam-se tratados com a maior facilidade. Quase todas as repúblicas concordaram que, no futuro, decidiriam suas questões por arbitramento. Era um acordo platônico, de bonito efeito, que parecia dar prazer a Blaine, e que, em suma, a nada obrigava. [...] Salvador, Guatemala, Haiti e São Domingos assinaram a obrigação de recorrer ao arbitramento, mas poucos meses depois houve uma guerra mortífera entre Salvador e Guatemala e as tropas de S. Domingos e Haiti. Ó fraternidade, ó lealdade americana e republicana. (Ibid., p. 86-87).

O autor também criticou a prática de notícias falsas que eram divulgadas em jornais norte-americanos, cuja fonte não poderia ser considerada honesta ou fidedigna. $\mathrm{E}$ ao fazer essa denúncia, acaba por esclarecer o desprezo que nutria por nações sul-americanas como Argentina e Uruguai, que deveriam ser tratadas com desconfiança. Vejamos o que Eduardo Prado escreveu a respeito das denúncias que teriam a intenção de influenciar no preço do café ou em outras questões econômicas:

A especulação é de uma imparcialidade provada; às vezes anuncia os mais lisonjeiros acontecimentos, outras vezes as catástrofes as mais terríveis. Em todo o caso, Nova Iorque é que é o ponto de concentração e de expedição dessas notícias. Os jornais americanos têm gasto muito dinheiro para ter notícias do Brasil nas diferentes crises agudas e periódicas da República; mas, em vez de receberem diretamente estas notícias, recebem-nas via Buenos Aires e Montevidéu, onde as notícias são todas exageradas e 
apimentadas com a má vontade de nossos irmãos argentinos e uruguaios, que são nossos inimigos [...]. (Ibid., p. 95).

Outra denúncia interessante foi feita por Eduardo Prado no sentido de reforçar o quanto a imprensa norte-americana divulgava fatos que ridicularizavam a atuação do ministro brasileiro em Washington naquela ocasião, Salvador de Mendonça. O mesmo se aproveitou da crítica para declarar o quanto que Washington se utilizava de uma fraternidade moderada no trato com o Brasil.

O ministro do Brasil em Washington, o Sr. Salvador de Mendonça, tem experimentado, muitas vezes, à sua própria custa, que, nos Estados Unidos, a sua entidade de ministro dos Estados Unidos do Brasil não merece nenhum respeito por parte da imprensa. S. Ex.a tem tido na sua carreira incidentes desagradáveis, que a imprensa americana há longa e maliciosamente glosado, sem ter em vista que S. Ex.a, na sua qualidade de republicano intransigente, histórico e tudo o mais, e pelo seu título de ministro de uma república, devia ser tratado com mais respeito. O Senhor ministro é amador de belas artes; tinha uma galeria de quadros, todos assinados pelos maiores pintores antigos e modernos. Era uma galeria que valia muitos milhões; $\mathrm{S}$. Ex.a mandou-a para Paris para ser vendida em leilão. Os peritos parisienses, encarregados da avaliação, declararam que os quadros eram todos falsos; S. Ex.a., em telegrama para Paris, disse que estava de boa fé e que tinha sido enganado. Retirou os quadros, e, ,mais tarde, ofereceu alguns deles à Academia de Belas-Artes do Rio de Janeiro, que comeu por lebres primorosas todos aqueles gatos à óleo, pois que esta anedota, que é apenas um pouco cômica para o nosso ministro e que só prova que S. Ex.a. não entende de pintura, e que foi roubado, comprando por enorme por enorme soma aquela galeria, foi decantada nos jornais de Nova Iorque, e o representante do Brasil coberto de ridículo. (Ibid., p. 93-94).

Esta denúncia vem seguida da crítica que Prado faz à má influência dos norteamericanos entre os brasileiros, principalmente no que tange à escravidão. Segundo o autor, o Brasil não teria conservado tanto tempo essa instituição não fosse a tentativa dos Estados Unidos de legitimá-la. Ademais, apontou a corrupção política e administrativa como inerentes ao funcionamento do governo americano.

Claramente, trata-se de um livro panfletário e regado de argumentações limítrofes e questionáveis, postura esta que não era desejada na Revista Americana. Para além de criticar as posturas corruptas dos Estados Unidos, o autor evidenciou o Brasil como um país que não foi original em virtude do comportamento de ter copiado os norte-americanos em suas leis políticas: “copiemos, copiemos, pensaram os insensatos. Copiemos e seremos grandes. [...] e como é muito da natureza humana imitar mais facilmente os vícios que as virtudes, a imitação das práticas corruptas norteamericanas é cousa muito natural. ”(Ibid., p. 100). Esse 
argumento que atrela a civilização norte-americana como aquela que corrompe os outros países do continente foi utilizada pelo autor no intuito de afirmar que este país não seria um espelho de civilidade e nem de moral.

A civilização não se mede pelo aperfeiçoamento material, mas sim pela elevação moral. $\mathrm{O}$ verdadeiro termômetro da civilização de um povo é o respeito que se tem pela vida humana e pela liberdade. Ora, os americanos têm pouco respeito pela vida humana. Não respeitam a vida de outrem e nem a própria. [...] Nos vários casos de linchamento de que temos notícia (no Brasil), há sempre um americano instigador e co-participante. Esses casos tem sido raros até e circunscritos à zona de São Paulo onde há americanos. O exemplo é, porém, funestíssimo, o contágio, rápido, tanto mais quanto a impunidade é certa. (Ibid., p. 101).

Em outras palavras, a intenção do autor foi a de reforçar o espírito americano como espírito de violência em contraposição ao espírito brasileiro, descrito como aquele que é "mais ou menos deturpado através dos séculos e dos amálgamas diversos do iberismo, é um espírito jurídico que vai, é verdade, à pulhice do bacharelismo, mas conserva sempre um certo respeito pela vida humana e pela liberdade." (Ibid., p. 102). Nesse sentido, o Brasil é visto como portador de uma moral e de uma civilidade e não fazia sentido tomar os Estados Unidos como exemplo, visto que

O espírito americano infundido nas populações é antes favorável ao capanga do que à gente do foro; é o estrangeiro, cujo prestígio é sempre grande, é o homem de cabelo louro e de olhos azuis sempre acatada pelos nossos negroides, influindo em favor da violência, nobilitando-o pela sai prepotência. $\mathrm{O}$ americano, mesclado com as camadas inferiores da população rural, não é um fator de progresso. Ele age sobre o meio e o meio reage sobre ele, havendo uma comunicação recíproca de defeitos que afoga a qualidade de ambos. (Ibid., p. 102).

De forma semelhante, o autor não elenca nenhuma contribuição intelectual por parte dos norte-americanos, mais do que aquela que foi influência dos europeus.

\section{CONSIDERAÇÕES}

A partir da análise feita acima, foi possível perceber que Eduardo Prado não foi convidado a se inscrever na história da Revista Americana, visto que criticava incisivamente não apenas os Estados Unidos, mas também, em seus discursos escritos de retomada de fatos históricos, dizia ser impossível qualquer tipo de aproximação entre os países latino americanos em virtude de seu passado de interesses econômicos apenas, de desorganização 
política e violência. Permitir que tais representações fossem postas a circular poderia significar a impossibilidade do sonho da paz por meio da cordialidade entre os povos americanos, visto que recontar a história em termos tão críticos e violentos apenas corroboraria para a criação de animosidades entre as nações e a não realização dos planos e sonhos desses intelectuais.

\section{REFERÊNCIAS}

BARROS, Francisco Reinaldo Amorim de. ABC das Alagoas: dicionário biobibliográfico, histórico e geográfico das Alagoas. Brasília: Senado Federal, Conselho Editorial, 2005. 2v. -- (Edições do Senado Federal ; v. 62-B).

BETHELL, Leslie. Brasil y “América Latina”. In: Prismas, Revista de história intelectual. Número 16, 2012, pp. 53-78.

BUENO, Clodoaldo \& CERVO, Amado Luiz. História da política exterior do Brasil. Brasília: Editora Universidade de Brasília, 2008.

CARDIM, Carlos Henrique. A luta pelo princípio da igualdade entre as nações - Rio Branco e Rui Barbosa na Conferência de Paz da Haia de 1907. In: II Conferência da Paz de Haia, 1907: a correspondência telegráfica entre o Barão do Rio Branco e Rui Barbosa / [Centro de História e Documentação Diplomática]. - Brasília: FUNAG, 2014.

CARVALHO, Elizabeth dos Santos de. O Barão do Rio Branco e a política de aproximação com os Estados Unidos. In: Anais da Biblioteca Nacional, v. 126, 2006. Páginas 69-138.

CASTRO, Fernando Vale. Pensando um continente: a Revista Americana e a criação de um projeto cultural para a América do Sul. Rio de Janeiro: Mauad X: FAPERJ, 2012.

CHARTIER, Roger. História Cultural: entre práticas e representações. Rio de Janeiro / Lisboa: Bertrand Brasil / DIFEL, 1990.

DANTAS, Carolina Vianna. O Brasil café com leite: história, mestiçagem e identidade nacional em periódicos. (Rio de Janeiro, 1903-1914). Orientadora: Martha Abreu. Tese (Doutorado) - Universidade Federal Fluminense, Departamento de História, 2007.

DEMARCHI, Ademir. Falácias americanas: do americanismo à unidade da América. Orientador: Antonio Dimas. Tese (Doutorado) - Universidade de são Paulo, Faculdade de filosofia, letras e ciências humanas, Departamento de Letras Clássicas e Vernáculas da Literatura Brasileira, 1997.

FABRIZ, Larissa Milanezi. Joaquim Nabuco: pan-americanismo, circulação de representações e relações de poder (1905-1910). Orientadora: Juçara Luzia Leite. Dissertação (Mestrado em História) - Universidade Federal do Espírito Santo. Centro de Ciências Humanas e Naturais, 2014.

FELDMAN, Luiz. Soberania e modernização no Brasil: Pensamento de Política Externa no Segundo Reinado e na Primeira República. In: Contexto Internacional. Rio de Janeiro, vol. 31, número 3, setembro/dezembro 2009, p. 535 - 592.

FISH, Stanley. Is there a text in this class? The authority of interpretative communities. London, 
England: Cambridge, Massachusetts, Harvard University Press, 1980.

GANZERT, Frederic William. 1934. The Boundary Controversy in the Upper Amazon between Brazil, Bolivia, and Peru, 1903-1909. Hispanic American Historical Review. 14 (4):427-449.

GASPARELLO, Arlete Medeiros. Delgado de Carvalho: Intervenção e projeto social na construção de uma disciplina escolar. In: Anais do XXVII Simpósio Nacional de História - Conhecimento histórico e Diálogo Social. Natal, RN, 2013.

GOES FILHO, Synesio Sampaio. Navegantes, bandeirantes, diplomatas: um ensaio sobre a formação das fronteiras do Brasil / Synesio Sampaio Goes Filho. - Ed. rev. e atual. - Brasília : FUNAG, 2015.

KOSELLECK, Reinhart. Futuro Passado: Contribuição à semântica dos tempos históricos. Rio de Janeiro: Contraponto-Ed. PUC-Rio, 2006.

MAGAlHÃES, Rejane M. Moreira. Presença de Ruy Barbosa em Haia. Rio de Janeiro: Fundação Casa de Ruy Barbosa, 2007.

MAGNOLI, Demétrio. O corpo da Pátria. São Paulo: Moderna/Unesp,1997.

MAGRI, Lucio. O movimento pacifista e a Europa. In: THOMPSON, Edward Palmer (Org.). Exterminismo e Guerra Fria. São Paulo, Brasiliense, 1985.

PEREIRA, Paulo José dos Reis. A política Externa da Primeira República e os Estados Unidos: a atuação de Joaquim Nabuco em Washington (1905-1910). In: Revista Brasileira de Política Internacional. Número 48. Páginas 111-128. 2005

PRADO, Eduardo. A Illusão Americana. Brasília: Senado Federal, Conselho Editorial, 2003 Revista Americana (1909-1919), Biblioteca Nacional do Rio de Janeiro, Periódicos - Microfilme: PR-SOR 06249.

RIBEIRO, Edgard Telles. A diplomacia cultural e o seu papel na política externa brasileira. Brasília: Funag, 1989.

SANTOS, Luís Cláudio Villafañe G. O dia em que adiaram o carnaval: Política Externa e a Construção do Brasil. São Paulo: Editora UNESP, 2010.

TAMBS, Lewis A. 1966. Rubber, Rebels, and Rio Branco: The Contest for the Acre. Hispanic American Historical Review. 46 (3):254-273.

VALE, Nayara Galeno do. Delgado de Carvalho e a História: trajetória e atuação de um "pardal de Clio" no campo intelectual do Rio de Janeiro (1931-1955). In: ANPUH -XXV SIMPÓSIO

NACIONAL DE HISTÓRIA. Fortaleza, 2009.

ZIMMERMANN, Augusto. "Rui Barbosa, o "águia de Haia": um breve estudo em homenagem ao centenário de sua participação na segunda Conferência de Paz de Haia". In: Revista Achegas. $n^{\circ} 33$, jan-fev 2007, pp. 14-31. (www.achegas.net) 
Larissa M. Fabriz é historiadora que pesquisa a história da América Latina, especializada em intelectuais do continente que publicaram entre os séculos XIX e XX, relações internacionais e Pan-americanismo. Possui licenciatura plena em História pela Universidade Federal do Espírito Santo (2010). É Mestre em História pelo PPGHIS, da Universidade Federal do Espírito Santo (2014), sob orientação da Professora Dra. Juçara Luzia Leite. A dissertação da autora explorou a performance do diplomata brasileiro Joaquim Nabuco enquanto este ocupou o cargo de embaixador em Washington entre 1909 e 1909. Atualmente, é doutoranda do mesmo programa, bolsista da CAPES, sob orientação da Professora Dra. Juçara Luzia Leite e desenvolve pesquisa para analisar o periódico Revista Americana, do início do século XX.

Esta obra está licenciada sob uma Licença Creative Commons. 